\title{
Rebeca Sanmartín Bastida (2017), La comida visionaria. Formas de alimentación en el discurso carismático feminino del Siglo XVI, prol. Catherine Davies, s.l., Splash Ediciones ${ }^{1}$
}

\author{
Recensão de Maria Luísa Malato \\ Universidade do Porto / Instituto de Literatura Comparada Margarida Losa
}

Este estudo de Rebeca Sanmartín Bastida, professora na Universidade Complutense de Madrid, abrange um corpus literário muito definido: os textos de devoção escritos por mulheres, saídos da pena de freiras ou beatas carismáticas (ou, indiretamente das suas discípulas ou confessores), especificamente em Castela (Espanha), nos séculos XV-XVI. A autora estuda neles o tema da alimentação, mas tem como escopo um subtema muito preciso: a análise da tópica do banquete celestial, presente nesses textos de devoção sob a forma de visões ou imagens literárias. Estes textos femininos (de índole religiosa e marcadamente autobiográficos) tornam-se, sob este intento invulgar, uma riquíssima fonte de informações sobre a vastíssima abrangência epistemológica dos estudos sobre alimentação. Das referências aos hábitos alimentares nos conventos castelhanos no limiar da Idade Moderna às tensões de poder nos claustros femininos, se vai aqui apresentado uma sobreposição de níveis que se descobrem em continuum: o fisiológico (da ingestão e digestão do alimento), o metafísico (da sensibilidade gerada pelo sensível), e o teológico (o da comunhão como visão ou antevisão da plenitude em Deus). Do caráter simultaneamente real, imaginário e utópico de tais escritoras "carismáticas" decorre a expressão que Rebeca 
Sanmartín Bastida colhe para o título, "a comida visionária".

Engana-nos se considerarmos reduzida a sua perspetiva espácio-temporal (porque restrita a Castela, no limiar da Idade Moderna). Ou se nos ficarmos pela conceção canónica da História da Literatura (já que o corpus é composto por textos que o tempo foi negligenciando, por serem textos de devoção, sobretudo por serem de autoria feminina, e de autoras desconhecidas, por todas estas razões afastados dos catálogos literários). Ou ainda se considerarmos a especificidade do sub-tema, a da metáfora da alimentação (pois tantas vezes a metáfora é lida como mero artifício decorativo). É surpreendente a complexidade social, económica, política, religiosa, literária, tal como é inesperada a "transversalidade simbólica" e a "metodologia interdisciplinar fundamental" que o corpus proporciona (cf. Prólogo de Catherine Davies a idem: vii). Muito mais do que um recorte espacial e temporal, um pretexto de Paraliteratura ou uma metáfora poética, a "comida visionária" é (enquanto processo fisiológico, metafísico ou teológico) uma estratégia retórica. Visa a persuasão de vários públicos, em diferentes espaços e tempos e, ainda enquanto ação religiosa, representa uma prática de afirmação de identidade (nomeadamente do estatuto da mulher). 0 estudo destes textos femininos, considerados menores pela História da Literatura canónica, obriga-nos a uma prática comparatística que tem como consequência a interseção das grandes áreas da Literatura Comparada: a Tópica/ Tematologia e o estudo dos temas, a Genologia e o estudo dos géneros, a Morfologia e o estudo das formas, os Estudos de Género e a escrita feminina, as relações espaciais e o diálogo entre local e universal, as relações históricas e a revisitação temporal. Na nossa perspetiva, é sobretudo deste seu indelével interesse para os estudos de Literatura Comparada que decorre o interesse que o livro possa ter para a História da Literatura, a História da Religião, a História da Medicina, a História das Ideias, a Sociologia do Corpo, a Psicologia Social, a ou, sob uma forma mais imediatamente reconhecível, os estudos sobre a Alimentação.

O curriculum de Rebeca Sanmartín Bastida parece ter sido uma lenta preparação para essa inusitada sensibilidade à "transversalidade simbólica" e à "metodologia interdisciplinar", de que também faz prova a extensa e variada Bibliografia, que é de toda a 
utilidade sublinhar (idem: 149-163). Tudo parece prepará-la para a transversalidade histórica, espacial, conceptual - exigida pelo estudo de tais textos. Os primeiros trabalhos académicos de Sanmartín Bastida incidiram sobre o medievalismo oitocentista (v.g., Imagenes de la Edad Média, 2002), passando a investigadora entretanto pela atenção aos fenómenos fisionómicos, ligados à teatralidade dos textos narrativos e à Retórica, especificamente centrada na Ação, ou seja nos pormenores da voz, movimentos do corpo (v.g., El arte de morir: la puesta en escena de un tratado del siglo XV, 2006). Um estudo publicado em 2012 sobre La representación de las místicas - e em particular o contexto europeu da produção e receção literária de Sor María de Santo Domingo - parece determinante para a aproximação dos estudos de Sanmartin Bastida aos elaborados por Caroline W. Bynum sobre as visionárias europeias (Holy Feast and Holy Fast: the religious significance of food to medieval women, de 1987). 0 corpus de Caroline Bynum, apesar da amplitude epistemológica, ignorava os escritos existentes na Península Ibérica. E dessa lacuna parte o estudo de Rebeca Sanmartín Bastida.

Este elemento lacunar não é de somenos importância para a leitura deste estudo em Portugal. Um dos seus muitos interesses passa paradoxalmente por ele não citar casos semelhantes na cultura portuguesa. Sendo tão próxima a literatura portuguesa da literatura espanhola (pelo menos nos séculos em apreço), até que ponto as investigações por fazer nos não devem conduzir a buscar semelhanças ou dissimilitudes? A lacuna, desde agora a descoberto, pode e deve dar azo a que se aceite o desafio de as procurar noutros tempos e lugares. 0 conhecimento, nas humanidades como nas ciências naturais, é feito por uma lenta circunstancial forma de voltar a percorrer os caminhos delineados por outros, para lhes encontrar, não raras vezas, outros pontos de partida ou de chegada. Tal foi, aliás, a principal premissa deste trabalho: circunscritas a um espaço de clausura ou semi-clausura, as mulheres aqui consideradas desenvolvem estratégias contidas, do ponto de vista do público visado. Mas são precisamente essas estratégias contidas que parecem hoje extraordinárias depois de a História das civilizações ter voltado a sua atenção para o espaço privado. Este livro começa precisamente por esse tributo aos que foram traçando caminhos mais ou menos solitários. É porque eles se foram repetindo que foram avançando. Depois 
de citar o livro de C. Bynum, Rebeca Sanmartín Bastida realça a importância de Norbert Elias, que tão amplamente influenciou a história da "civilização dos costumes" (idem: 2 e 3) e de Roland Barthes, que concebeu a utilidade de uma "semiologia do alimento" para entendimento da nossa indispensável vida em comunidade (idem: 3). Junta-lhes ainda outros nomes, sobre os quais alicerçou a sua investigação: os estudos de Le Goff sobre a história da alimentação, ou os de Michel Foucault sobre o discurso com que moldamos o corpo humano...

Alerta-nos também para o muito que há ainda a fazer nos estudos sobre escrita feminina. Se o espaço masculino permite a ostentação pública (que vai da edição dos textos à exibição do seu valor intelectual, passando pela afirmação da sua razão e vontade), o espaço feminino vive do seu oposto retórico: a humildade dos gestos e das palavras, a vulgarização do pensamento ou a afirmação da irresponsabilidade quando sob a suspeita de heterodoxia. As mulheres escrevem, muitas vezes às escondidas, textos de uso pessoal, por vezes encorajadas ou desencorajadas pelos seus confessores. Aparentam quase não ter intelecto, são quase só corpo animal. Não descrevem geografias urbanas, mas falam muito da cozinha, huis-clos onde lhes é permitido trabalhar. As metáforas alimentares decorrem desse raro ambiente profano que lhes é familiar. 0 prazer material do alimento torna sensível o prazer espiritual. Isabel de Schönau ou Margarita Ebner afiançam a semelhança do amor de Deus à doçura do mel ou do açucar, à delicadeza da maçã ou da canela. Matilde de Hackeborn compara a sua alma a uma cozinha: nela trabalha o Espírito Santo, confeccionando raros paladares divinos. Catarina de Siena refere o processo digestivo do Verbo divino, esse camareiro que traz e leva o doce fruto da caridade divina. Mesa, alimento e camareiro são, aliás, uma trindade metafórica que em alguns casos se aproxima da Trindade cristã (idem: 11 et passim). Tais metáforas permitem-nos facilmente compreender que os alimentos ingeridos sejam simultaneamente, elementos simples e quotidianos (que asseguram uma compreensão imediata) e um paradigma elaborado (que exige a quem os quer compreender uma sobreposição dos níveis de leitura). “Así, entre la comunión, pieza fundamental de su espiritualidade, y el ayuno, consubstancia a su penitencia, estas mujeres 
encontrarán nuevos modos de concebir el alimento, com la maternidade o el deseo como adiciones inexcusables" (idem: 4).

Esses novos modos de conceber o alimento levam Rebeca Sanmartín Bastida a dividir a sua obra em três capítulos, organizando de forma tripartida os argumentos: as formas de alimentação, os modos de mística lactante e os diferentes pontos de vista sobre o jejum feminino. Ainda que tais argumentos revelem bastante autonomia entre si - com utilidade se leem sequencialmente, por servir cada um de contexto ao seguinte e por entre eles existir uma sublimação crescente, que vai do material sólido ao líquido e do líquido ao aéreo, com diferentes tipos de negação da "natureza corpórea".

O primeiro, "Formas de alimentación", debruça-se sobre o tipo de alimentação identificada com o prazer do encontro com Deus. Nesta parte se incluem as visões utópicas do Banquete Celestial, mas também a sua antítese disfórica, as descrições do “cadáver adiado", do corpo que não vive já das coisas terrenas e se delicia com o Banquete Celestial, ainda em vida. Alguns alimentos induzem à ligação entre os dois mundos, o material e o espiritual, o aprazível e o desprezível. Por exemplo, a ingestão do pus dos leprosos registada em alguns textos é, para quem a pratica, uma forma de alimento espiritual, a forma extrema da comunhão com a miséria humana. A ingestão de incenso, registada em outros escritos (idem: 17), pode ser relacionada com o poder de secura da carne, uma das propriedades do incenso. Não devemos esquecer que, nestas épocas, quando não existiam muitas formas de atrasar o processo de putrefação, era objeto de admiração o corpo sem humidade, inodoro (dito até perfumado, com odor divino), como se tivesse sido embalsamado. Pelo contrário, a gordura do corpo era um visível sinal de gula, forma básica de luxúria ou generalizada afeição aos prazeres materiais. 0 pão - molhado em leite, até porque o leite é então concebido como matéria similar ao sangue (idem: 87) ou em azeite, produto da maceração da azeitona, e imagem da sublimação do sofrimento humano - é o alimento que por excelência conduz à perceção do divino. Pelo contrário, a ingestão da carne é identificada com a aceitação do mal. Neste sistema simbólico, a assimilação do alimento animal conduz á valorização da nossa animalidade; por outro lado, o demorado jejum é uma forma de preparação para a Eucaristía, momento supremo de ingestão do 
alimento divino. A comunhão torna-se um momento único de refeição festiva; e a hóstia um alimento concentrado e tendencialmente suficiente. Joana da Cruz imagina então o Banquete Celeste como uma eucaristía em que a variedade se realiza na unidade da hóstia: “[...] salieron a deshora infinitas hostias y rosquillas y panecitos más dulces y blancos y sabrosos que de alfeñique y azúcar y alcorzas, y más olorosos y preciosos que todos los olores y preciosidades del mundo ni del cielo, por cuanto eran manjares divinales que procedían del poderoso y eterno Dios. Las cuales hostias y rosquillas y panecitos tan sobreexcelentes manaban y procedían de la suavísima y purísima masa, y caían a las bocas de todos los Bienaventurados de la corte del cielo, desde Nuestra Señora, la Virgen Maria, hasta el más pequeño" (Juana de la Cruz apud idem: 25).

Um segundo capítulo, "La mística lactante", trata da representação de Deus como mãe que alimenta amorosamente os filhos. O capítulo recupera representações outrora mais comuns, como a de Deus, ou a de Cristo, possuidores do dom feminino da amamentação. Na vida de Santa Catarina de Siena se festeja esse dom em Cristo, capaz de apaziguar aquela fome de imortalidade, sentido pelo mortais. Os escritos de Teresa de Jesus são aqui analisados pela importancia que dão à comparação entre aleitamento e amor divino. Escreve Santa Teresa de Jesus no Camino de perfección: "Y advertid mucho a esta comparación, que me parece cuadra mucho: está el alma como un niño que aún mama cuando está a los pechos de su madre, y ella, sin que él paladee, échale la leche en la boca por regalarle". Mas os seus textos revelam também detalhes icónicos, mais próximos da Pintura que da comparação literária. Nas Séptimas Moradas, Santa Teresa descreve um Criador, de cujos generosos peitos jorram água e leite para saciar seus filhos: “[...] salen unos rayos de leche que toda la gente del castillo conforta; que parece quiere el Señor que gocen de alguna manera de lo mucho que goza el alma" (apud idem: 73). Devemos a este propósito salientar que a obra de Rebeca Sanmartín Bastida alerta para estas representações icónicas (nomeadamente do Banquete Celestial e da Mística da lactancia), ainda que não apresente ilustrações. Com muita pertinência, a investigadora constata a aparente comodidade com que as visionárias se servem destas imagens de um Deus que amamenta. A invulgaridade dessas imagens nos días de hoje, quando o excesso do 
consumismo obriga o gourmet a ser minimalista, e a representação de um Deus andrógino é heterodoxa e provocadora, leva-a a perguntar se assim seria nos séculos XV e XVI. No discurso do Humanismo, parecem cruzar-se as Virgens amamentando o Menino e algunas imagens, talvez mais marcadas pela estética medieval, de Cristos que deixam cair pingos de leite e sangue dos seus peitos. Entre 1500 e 1800, as esculturas e pinturas (que são ainda a Bíblia dos pobres) divulgam as imagens da Virgem-Mãe, dando o peito a seu Filho, ao mesmo tempo que os tratados de medicina defendem a importância do leite materno. Os relatos das místicas parecem ir ao encontro de uma mesma mensagem (idem: 69). Mas, ao contrário do pensamento dominante, os relatos destas mulheres parecem não ter uma finalidade utilitária, não mostrando preocupação alguma com a limpeza de sangue, a transmissão da imoralidade ou da doença, ou as obrigações da mulher casada (idem: 91). Falam da amamentação como prazer puro, tanto para a criança como para a ama ou mãe, falam do prazer de dar e receber, sem que aparentemente sejam lidas como escritoras heterodoxas, ainda quando censuradas por razões teológicas. Este Deus que amamenta vai curiosamente desaparecendo à medida que a mulher vai ficando mais presa às funções domésticas. Como ler estas transições? A amamentação pode ao mesmo tempo ser lida como exaltação do feminino e como redução da identidade feminina às suas funções procriadoras. Por isso também Sanmartín Bastida nos previne dos possíveis preconceitos e pré-conceitos da investigação (idem: v.g., 93-4).

O terceiro capítulo, "El hambre negociada", trata precisamente destas derivações interpretativas, mais claras quando consideradas ao longo do tempo. 0 julgamento exercído sobre estas mulheres pelos seus intérpretes (os confessores, os teólogos, os historiadores, os médicos ou os psicólogos) tem variado muito: mais depressa se compreendem as razões de quem julga do que as de quem é julgado. Certo é que o jejum destas religiosas parece libertá-las dos constrangimentos da vida em clausura. Retoricamente, o jejum funciona como uma estratégia ativa-passiva: ao mesmo tempo que a penitente age (não comendo, não cedendo à tentação do demónio), ela alega, quase sempre, a total submissão a um poder divino que a proteje, inspira e sacia. A abstinência extrema é assim, genericamente, um sinal de excepcionalidade, em que deixa de haver regras. Por ser difícil para os demais, a 
renúncia da religiosa ao alimento indicia um domínio completo da natureza animal, e um camino para a natureza divina. Sancionado pelas canonizações, e divulgado pelas hagiografías, o excesso ascético é significativamente mais comum nas santas que nos santos. Tinham muito peso para as mulheres os exemplos de Hildegarda Von Bingen, Ângela de Foligno, Catarina de Siena, Santa Brígida ou Santa Teresa de Jesus (idem: 95-97). A magreza decorrente contribuiria também para uma aparência andrógina. A mulher (sem peito volumoso, sem formas de anca definidas, muitas vezes sem menstruação) aproximase da representação do poder masculino (cf. Lang apud idem: 99), da representação desse Cristo andrógino, de que se tinha falado já (ibidem), e da imaterialidade de Deus (cf. idem: 107). Até que ponto enganam ou querem engañar estas mulheres sem regra? Manipulam ou são manipuladas? Esta excepcionalidade feminina gera, como é expectável, muitas desconfianças, movidas por diferentes argumentos, de ordem social, teológica, historiográfica, farmacológica, médica ou psicológica. Já em 1401 um tratado de Jean Gerson, De distinctione verarum revelationum a falsis, alertava para a possível falsidade de jejuns extremos: citando um caso conhecido, o autor suspeita da sua autenticidade, vê os excessos da abstinência e da gula como processos simétricos, que denunciam falhas semelhantes (idem: 139). A partir da Contra-Reforma, os procesos de canonização, e consequentemente as hagiografías, vão desvalorizando a abstinencia radical como prova de santidade. 0 nojo do alimento, por vezes considerado uma perturbação dos rituais religiosos - desde logo o das refeições comunitárias - será depois condenado pelo pensamento iluminista, como comportamento induzido, fanático, anti-natura. Começa a partir daí a patologização do fenómeno. Para o leitor do século XXI, o comportamento de algumas destas mulheres apresenta por vezes inegáveis similitudes com o que designamos "anorexia". As biografías ou autobiografías denunciam ingenuamente o seu temperamento controlado; o registo obsessivo do alimento; a oposição à autoridade familiar, e em especial à figura materna; os processos de imitação, por influência de leituras ou companhias; a culpa associada ao apetite; a hiperatividade; as insónias; os momentos irregulares de euforia e disforia; o consumo estratégico de frutos secos ou de água; o empenho até na confeção de alimentos para os outros, prova última do seu dominio do corpo... Os relatos de 
Maria de Santo Domingo ou de Maria de Velo y Cueto parecem ilustrá-lo. Mas a expressão "Holy Aneroxia" - atribuída, em 1985, por Rudolph M. Bell, a relatos femininos muito semelhantes aos estudados por Rebeca Sanmartín Bastida - não deixa de abafar certas particularidades que hoje tendemos a negligenciar. Os séculos XV e XVI, sobretudo para as faixas da população aquí abrangidas, tinham fenómenos de escassez de alimentos muito frequentes, e muitos dos relatos biográficos referem até a fome a que o corpo de muitas mulheres foi sendo habituado. Nesses tempos, o controle da fome era valorizado num contexto religioso: não raras vezes, ele correspondia à generosidade dos bens partilhados. 0 processo anorético apresenta-se tão imbricado no comportamento místico que ele não pode ser confundido com os fenómenos de histerismo feminino (descritos desde Freud e ainda tão vivos na imagética da atual psicología) ou com os motivados pela pressão estética dos média. A patologização do processo, ocorrida sobretudo no século XX, enfatiza por vezes ainda uma conceção sexista, e impossibilita a ampla compreensão da questão. Impede também a consideração da excepcionalidade do processo, ignorando-se nele desde logo a dimensão religiosa. E se Rudolph Bell tem razão ao classificar estas religiosas como anoréxicas que se opõem à autoridade masculina, não será a sua patologização uma forma ainda de abafar essa oposição à autoridade?

O livro de Rebeca Sanmartín Bastida termina, significativamente, com muitas outras perguntas: "Quizás entonces el ayuno sea también un camino de secularización que se inicia de un modo casi privilegiado antes que otros, antes incluso que el siglo decimonónico abra famosamente la caja de los truenos con un gran sacudimiento de los cimientos de la fe" (2017: 148). 


\section{NOTA}

10 presente trabalho foi realizado no âmbito do Projeto ALIMENTOPIA / Utopian Foodways, financiado por Fundos FEDER através do Programa Operacional Competitividade e Internacionalização - COMPETE 2020 e por Fundos Nacionais através da FCT - Fundação para a Ciência e a Tecnologia (PTDC/CPC-ELT/5676/2014 | POCI-01-0145-FEDER-016680). 